\title{
Syndromic surveillance to assess the potential public health impact of the Icelandic volcanic ash plume across the United Kingdom, April 2010
}

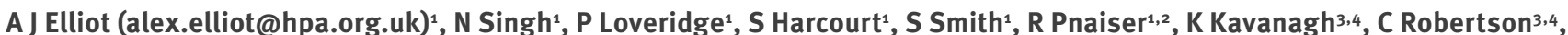 \\ C N Ramsay 3 , J McMenamin33, A Kibble ${ }^{5}$, V Murray ${ }^{6}$, S Ibbotson $^{1}$, M Catchpole7, B McCloskey $^{8}$, G E Smith ${ }^{1}$ \\ 1. Real-time Syndromic Surveillance Team, Health Protection Agency, Birmingham, United Kingdom \\ 2. Royal College of General Practitioners Research and Surveillance Centre, Birmingham, United Kingdom \\ 3. Health Protection Scotland, Glasgow, United Kingdom \\ 4. Department of Mathematics and Statistics, University of Strathclyde, Glasgow, United Kingdom \\ 5. Centre for Radiation, Chemicals and Environmental Hazards, Health Protection Agency, Birmingham, United Kingdom \\ 6. Centre for Radiation, Chemicals and Environmental Hazards, Health Protection Agency, London, United Kingdom \\ 7. Centre for Infections, Health Protection Agency, London, United Kingdom \\ 8. London Regional Director's Office, Health Protection Agency, London, United Kingdom
}

Citation style for this article:

Citation style for this article: Elliot AJ, Singh N, Loveridge P, Harcourt S, Smith S, Pnaiser R, Kavanagh K, Robertson C, Ramsay CN, McMenamin J, Kibble A, Murray V, Ibbotson S, Catchpole M, McCloskey B, Smith GE. Syndromic surveillance to assess the potential public health impact of the Icelandic volcanic ash plume across the United Kingdom, April 2010. Euro Surveill. 2010;15(23):pii=19583. Available online: http://www.eurosurveillance.org/ViewArticle.aspx?Articleld=19583

This article has been published on 10 June 2010

The Eyjafjallajökull volcano in Iceland erupted on 14 April 2010 emitting a volcanic ash plume that spread across the United Kingdom and mainland Europe. The Health Protection Agency and Health Protection Scotland used existing syndromic surveillance systems to monitor community health during the incident: there were no particularly unusual increases in any of the monitored conditions. This incident has again demonstrated the use of syndromic surveillance systems for monitoring community health in real time.

\section{Introduction}

The Eyjafjallajökull volcano in Iceland began erupting on 14 April 2010. Due to the prevailing weather conditions the resulting plume of volcanic ash spread towards the United Kingdom (UK) and mainland Europe. On 16 April the ash cloud was located over the UK and air travel restrictions were introduced initially across Scotland and then the rest of the UK due to the threat the ash posed to aircraft safety. Restrictions were lifted on 20 April.

Weather conditions meant that most of the ash cloud remained at high altitude but some light ash falls were reported in Scotland and other parts of the UK. There were also anecdotal reports of the detection of various sorts of sulphurous odours in parts of Scotland (particularly in Shetland during the initial days following the eruption). As part of a public health risk assessment, the Health Protection Agency (HPA) in England and Health Protection Scotland (HPS) both used existing syndromic surveillance systems to establish whether there was any evidence of a population-based impact on public health.

The HPA and HPS both have syndromic surveillance systems that are routinely used to monitor seasonal outbreaks of disease, e.g. influenza and norovirus infection, and provide surveillance support during incidents and events where there could be a potential impact on local community health, e.g. flooding, industrial fires, large-scale chemical releases and geopolitical meetings [1-4].

During the period the volcanic ash cloud was over the UK, these syndromic surveillance systems were used to monitor a range of symptoms and clinical indicators, chosen for their association with the potential health effects of exposure to volcanic ash, such as irritation of the eyes and upper respiratory tract.

\section{Air quality and syndromic surveillance systems in the United Kingdom \\ Air quality monitoring data}

UK air quality is monitored by the Automatic Urban and Rural Network (AURN), in more than 100 sites within designated urban and rural areas. These automatic air quality monitoring stations measure a range of pollutants including nitrogen oxides, sulphur dioxide, ozone, carbon monoxide and particles of diameter of less than $10 \mu \mathrm{m}\left(\mathrm{PM}_{10}\right)$. An air quality banding system is used to estimate the levels of air pollution and the potential effect on public health ranging from Low, when effects of air pollution are unlikely to have any health effects, to Moderate, when mild effects may be noticed by sensitive individuals, to High and Very High, when sensitive individuals may experience significant effects requiring intervention to relieve the effects [5].

Other than the reports of light ash falls and anecdotal reports of sulphurous smells over parts of Scotland, provisional air quality monitoring data from AURN showed no evidence of pollution associated with the eruption. Levels of $\mathrm{PM}_{10}$ and sulphur dioxide 
were typically normal and there was no evidence of increased pollutant levels that could be attributed to the volcano $[6,7]$.

\section{Data from the Health Protection}

Agency for England

The HPA Real-time Syndromic Surveillance Team leads the production and development of information to guide public health action through syndromic surveillance systems that use data from a telephone health advice service of the National Health Service, NHS Direct, and two general practitioner surveillance systems, the HPA/QSurveillance and the Royal College of General Practitioners Weekly Returns Service systems [8-10]. Data from the three systems were routinely monitored; however, data from the HPA/QSurveillance system were predominantly used to produce the analyses and interpretations required during the volcanic ash incident and are therefore presented in this report.

The HPA/QSurveillance syndromic surveillance system is a large, general practice-based network comprising more than 3,500 practices and a weekly patient population of more than 23 million. The system covers the UK, but as there is currently no coverage available in Scotland and limited coverage across Wales and Northern Ireland, the system has maximal population representation across England, which has an estimated population of 51.5 million. Weekly incidence rates per 100,000 practice population were monitored for a range of clinical indicators and standardised incidence ratios calculated to identify countries and regions within the UK with unusually high incidence rates. The clinical indicators monitored during the volcanic ash cloud incident were:

- asthma

- conjunctivitis

- allergic rhinitis

- wheeze

- lower respiratory tract infection

- upper respiratory tract infection.

\section{FIGURE 1}

Weekly incidence rate of selected clinical indicators, 1 February - 3 May 2010 (weeks 6-18) against a three-year mean weekly incidence rate, United Kingdom
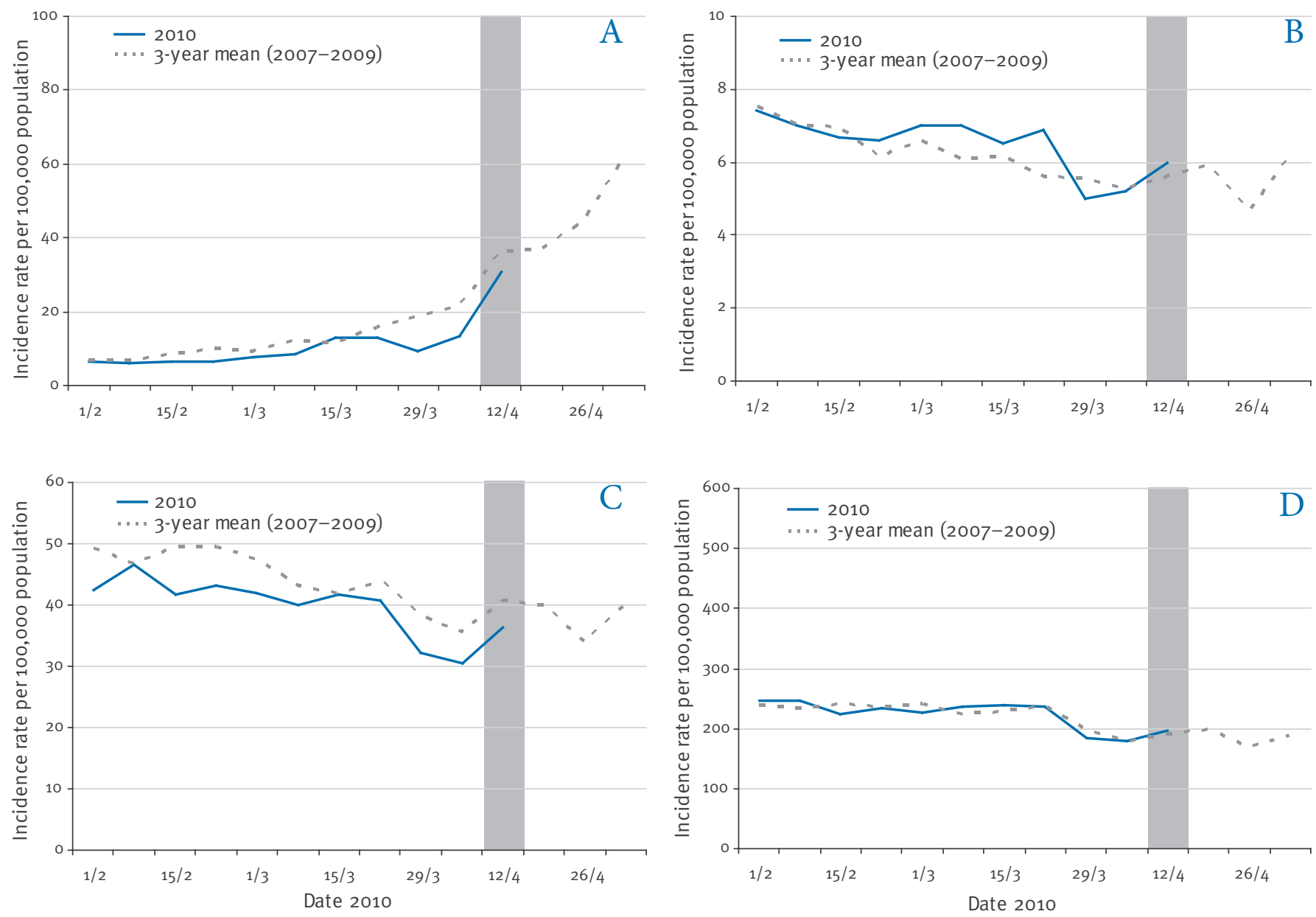

A: allergic rhinitis; B: asthma; C: conjunctivitis; D: upper respiratory tract infections.

The week during which the Icelandic volcanic ash cloud was located over the United Kingdom (16-20 April 2010) is illustrated by a vertical grey bar. For presentational purposes, historical data have been adjusted by incorporating a two-week lag to compensate for differences in calendar dates and public holiday periods between 2010 and previous years included within the three-year (2007-2009) mean incidence rate. Source: Health Protection Agency/QSurveillance system. 
During the week commencing 12 April 2010 (epidemiological week 15) all indicators increased in incidence (Figure 1). In the UK, weeks 13 and 14 (weeks commencing 29 March and 5 April 2010 respectively) contained public holidays, when access to general practitioner services is limited. This affects consulting behaviour and therefore incidence rates are artificially low. Routine statistical analysis of the HPA/QSurveillance data illustrated several statistically significant standardised incidence ratios. However, on further analysis, taking into account previous weeks' data and historical seasonal and public holiday trends, these were not considered unusual for the time of the year. There were no unusual rises detected in indicators in the HPA/NHS Direct and Weekly Returns Service surveillance systems routinely used throughout the incident.

\section{Data from Health Protection Scotland}

The respiratory team within HPS similarly leads the production and development of information to guide public health action through a syndromic surveillance system that uses data from NHS 24, a telephone health advice and treatment service. NHS 24 covers all of Scotland, which has an estimated population of 5.2 million, and data can be analysed by area of residence to determine the number and proportion of calls recording relevant symptoms. Daily data from this dataset were used to produce analyses and interpretations during the volcanic ash incident. The key symptoms monitored were:

- difficulty breathing

- eye problems

- cough

- rash.

Daily data were examined for the absolute number of NHS 24 calls allocated to specific syndrome categories. During 16-20 April 2010, when the ash cloud was located over the UK, there were no national exceedances for any of the key syndromes (Figure 2). During the period before the ash cloud there were a number of small daily exceedances in calls for difficulty breathing and eye problems compared with those expected for the period. These were evident at either an all Scotland or administrative healthcare area (NHS board) level, exceeding the upper limit of the $99 \%$ confidence interval for the number of calls received. Data for call proportions (percentage of total calls) were also examined for the same syndromes taking into account comparisons with historical syndrome baselines: there were no unusual rises in these proportions during the incident.

\section{Discussion}

During the volcanic ash incident, a variety of data sources were analysed and interpreted to determine if there were any unusual increases in any of the symptoms or indicators. We detected rises in general practitioner-based diagnoses of asthma, allergic rhinitis, conjunctivitis and respiratory conditions (Figure 1); however, these increases were to be expected at that time of year, most probably because of increasing pollen levels and possibly elevated ozone levels that were not associated with the volcanic eruption [11]. Despite the anecdotal reports of various sorts of sulphurous odours in parts of Scotland, extensive environmental monitoring of ambient air, rainwater, snow and grass also demonstrated that the eruption had little measureable impact on the UK and that any exposure would have been low and not likely to have had a significant impact on health. For example, air quality monitoring stations around UK did not show any increase in pollutants that could be associated with the eruption (e.g. $\mathrm{PM}_{10}$ and sulphur dioxide) $[6,7]$. The incident also followed a series of public holidays (occurring during weeks 13 and 14) during which access to general practitioner services was limited, which is known to artificially lower the incidence rates of a range of general practitioner-based diagnoses recorded by the HPA/ QSurveillance system. We used historical baseline data to determine that the reported trends (and effects of public holidays) were similar to previous years (Figure 1). These non-volcano-related factors led to an expected rise in several indicators during week 15. Despite these complexities in interpreting the data, the ability to use statistical methods to detect unexpected trends in the data ensured that we were confident that there were no population-based increases in morbidity associated with the ash cloud.

During this incident syndromic surveillance systems were the only sources of real-time health data. These syndromic data were used in conjunction with other

\section{FIGURE 2}

Daily number of telephone calls received for selected clinical indicators, 1 February - 3 May 2010 (weeks 6-18), Scotland
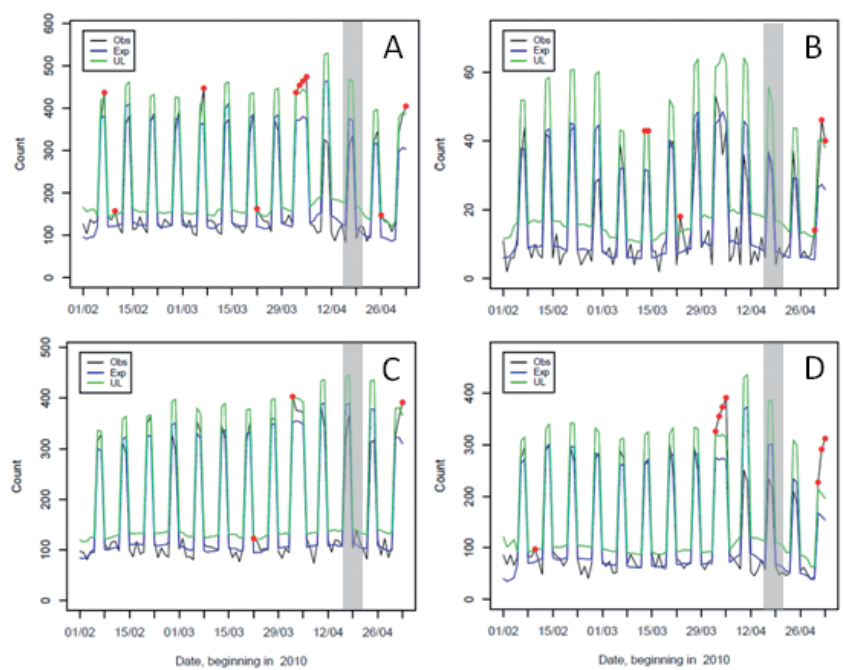

Dato, beginning in 2010

A: difficulty breathing; B: eye problems; C: rash; D: cough.

Data are displayed as counts of observed calls (Obs) and expected calls (Exp), upper $99 \%$ confidence limit (UL) and $99 \%$ confidence limit exceedances (red dots).

The period during which the Icelandic volcanic ash cloud was located over the United Kingdom (16-20 April 2010) is illustrated by a vertical grey bar.

Source: Health Protection Scotland/NHS 24. 
data sources including environmental monitoring data to provide reassurance that there were no populationlevel adverse health effects caused by exposure to the volcanic ash cloud. During such a high-profile and uncertain situation, there is great value in having health effect data to complement available environmental monitoring and exposure data. This approach provides triangulation of data sources and adds further confidence to the public health risk assessment. It is also very valuable to be able to give the public appropriately reassuring messages in real time about the likely impact on health $[12,13]$.

In Scotland, NHS 24 call data were examined on a daily basis for the absolute number of calls and call proportion (percentage of total calls) allocated into specific syndrome categories (Figure 2). Call patterns (e.g. a peak in total number of calls over the weekend and during public holidays) were considered when assessing whether call volumes were at normal levels or in excess of that normally observed. The observed daily exceedances in calls reporting difficulty breathing and eye problems were examined in respect of the nature of the call, including age, sex and location of the patient, temporal distribution and call disposition (whether the patient was just reassured, referred for further routine medical attention or sent to hospital urgently by ambulance). We concluded that these calls were not indicative of an unusual pattern and were in keeping with the expected pattern from previous seasons.

Syndromic surveillance systems have previously been shown to provide real-time tracking of disease outbreaks and they can provide earlier warning of community-based activity compared with traditional laboratory-based reporting systems. A potential limitation of these syndromic systems is a lack of specificity; however, it has previously been shown that there is a good association between syndromic surveillance data and laboratory data $[2,14]$.

A potential confounder in this incident was increasing pollen levels commonly experienced at that time of year [11], as the generic indicators selected for their association with exposure to ash are equally sensitive for monitoring hay fever, e.g. wheeze, allergic rhinitis, eye problems and difficulty breathing. However, the rise in these indicators was as expected for the time of year. If the rate or magnitude of rise had been significantly above the expected level we may have been able to attribute it to the ash. This lack of detectable health effect is also supported by environmental monitoring data, which demonstrated that exposure to volcanic ash would have been very low and not likely to have had a significant effect on health.

Syndromic surveillance systems have previously been used to track events of major public health impact including influenza pandemics, heat waves and flooding. This incident has further demonstrated the benefit of using national syndromic surveillance systems for monitoring community health in real-time to assess the impact of unforeseen circumstances and help develop clear evidence-based health protection messages.

\section{Acknowledgements}

We thank Dr Jill Meara, Dr Bob Maynard and Andrew Tristem (HPA Centre for Radiation, Chemical and Environmental Hazards), Professor Julia Hippisley-Cox (Nottingham University, UK, QSurveillance) and Dr George Crooks (NHS 24) for critiquing the manuscript and providing helpful comments. We are also grateful to Egton Medical Information Systems Ltd (EMIS) and the EMIS practices who voluntarily contribute their data to the HPA/QSurveillance database and to NHS 24 who contribute their data to HPS and HPA for analysis.

\section{References}

1. Elliot A. Syndromic surveillance: the next phase of public health monitoring during the $\mathrm{H}_{1} \mathrm{~N}_{1}$ influenza pandemic? Euro Surveill. 2009;14(44). pii=19391. Available from: http://www. eurosurveillance.org/ViewArticle.aspx?Articleld=19391

2. Loveridge P, Cooper D, Elliot AJ, Harris J, Gray J, Large $\mathrm{S}$, et al. Vomiting calls to NHS Direct provide an early warning of norovirus outbreaks in hospitals. J Hosp Infect. 2010;74(4):385-93.

3. Meyer N, McMenamin J, Robertson C, Donaghy M, Allardice G, Cooper D. A multi-data source surveillance system to detect a bioterrorism attack during the G8 Summit in Scotland. Epidemiol Infect. 2008;136(7):876-85

4. Health Protection Scotland (HPS). Weekly situation report influenza A H1N1v. 24-31 August 2009, week 35. Glasgow: HPS. Available from: http://www.documents.hps.scot.nhs.uk/ respiratory/swine-influenza/situation-reports/weekly-h1n1vsitrep-2009-09-03.pdf

5. UK Air Quality Archive. UK air quality objectives and air pollution bandings and index and the impact on the health of people who are sensitive to air pollution. AEA Technology. [Accessed 10 May 2010]. Available from: http://www.airquality. co.uk/standards.php\#band

6. UK Air Quality Archive. The Eyjafallajokull volcanic ash cloud and its effects on UK air quality. Update 06 May 2010. Didcot: AEA Technology; 2010. Available from: http://www.airquality. co.uk/news/Eyjafjallajokull_Volcanic_Ash_Cloud_06may2010_ AURN_update.pdf

7. UK Air Quality Archive. The Eyjafallajokull volcanic dust cloud and UK air quality. 15/04/2010. 2010. Available from: http:// www.airquality.co.uk/news/The_Eyjafallajokull_Volcanic_ Dust_Cloud_and_UK_Air_Quality_v2.pdf

8. Fleming DM. Weekly Returns Service of the Royal College of General Practitioners. Commun Dis Public Health. 1999;2(2):96-100.

9. QResearch. QSurveillance practice information sheet. [Accessed 10 May 2010]. Available from: http://www. qresearch.org

10. Smith GE, Cooper DL, Loveridge P, Chinemana F, Gerard E, Verlander N. A national syndromic surveillance system for England and Wales using calls to a telephone helpline. Euro Surveill. 2006;11(12). pii=667. Available from: http://www. eurosurveillance.org/ViewArticle.aspx?Articleld $=667$

11. Ross AM, Corden JM, Fleming DM. The role of oak pollen in hay fever consultations in general practice and the factors influencing patients' decisions to consult. Br J Gen Pract. 1996;46(409):451-5.

12. Health Protection Agency (HPA). Statement on health effects of Icelandic volcanic ash plume. 15 Apr 2010. London: HPA; 2010. Available from: http://www.hpa.org.uk/NewsCentre/NationalPr essReleases/2010PressReleases/100415volcanicash/

13. Health Protection Scotland (HPS). Latest update on volcanic ash in Scotland. 16 April 2010. Glasgow: HPS; 2010. Available from: http://www.hps.scot.nhs.uk/news/spdetail.aspx?id=350

14. Cooper DL, Verlander NQ, Elliot AJ, Joseph CA, Smith GE. Can syndromic thresholds provide early warning of national influenza outbreaks? J Public Health (Oxf). 2009;31(1):17-25. 